\title{
Effects of Carbon Ion Beam Irradiation on Phenotypic Variations and Biochemical Parameters in Early Generations of Soybean Plants
}

\author{
Xue Wang ${ }^{1,2}$, Chang-Kai Liu ${ }^{1} \mathbb{D}$, Bing-Jie Tu ${ }^{1,2}$, Yan-Sheng Li ${ }^{1}$, Qiu-Ying Zhang ${ }^{1,3, *}$ and Xiao-Bing Liu ${ }^{1}$ \\ 1 Key Laboratory of Mollisols Agroecology, Northeast Institute of Geography and Agroecology, CAS, \\ Harbin 150081, China; wangxue16@mails.ucas.edu.cn (X.W.); liuchangkai@iga.ac.cn (C.-K.L.); \\ tubingjie17@mails.ucas.edu.cn (B.-J.T.); liyansheng@iga.ac.cn (Y.-S.L.); liuxb@ga.ac.cn (X.-B.L.) \\ 2 University of Chinese Academy of Sciences, Beijing 100049, China \\ 3 Innovation Academy for Seed Design, Chinese Academy of Sciences, Harbin 150081, China \\ * Correspondence: zhangqiuying@iga.ac.cn; Tel.: +86-451-86601320; Fax: +86-451-86603736
}

Citation: Wang, X.; Liu, C.-K.; Tu, B.-J.; Li, Y.-S.; Zhang, Q.-Y.; Liu, X.-B. Effects of Carbon Ion Beam Irradiation on Phenotypic Variations and Biochemical Parameters in Early Generations of Soybean Plants. Agriculture 2021, 11, 98. https:// doi.org/10.3390/agriculture11020098

Received: 7 December 2020

Accepted: 21 January 2021

Published: 25 January 2021

Publisher's Note: MDPI stays neutral with regard to jurisdictional claims in published maps and institutional affiliations.

Copyright: (c) 2021 by the authors. Licensee MDPI, Basel, Switzerland. This article is an open access article distributed under the terms and conditions of the Creative Commons Attribution (CC BY) license (https:// creativecommons.org/licenses/by/ $4.0 /)$.

\begin{abstract}
Understanding the characteristics of carbon ion beam irradiation-induced mutation is essential to its potential application in plant breeding. A carbon ion beam-mutagenized soybean population was generated from the newly released soybean variety Dongsheng 28 , with irradiation dosages of $100 \mathrm{~Gy}, 120 \mathrm{~Gy}$ and $140 \mathrm{~Gy}$. Many phenotypic variations and novel mutants with heritable tendencies including plant height mutants, sterile mutants, early mature mutants, rolled leaves and short petioles mutants, yield-related mutants and lodging-resistant mutants were identified. Diverse variations in seed size, seed protein and oil concentration were found. Increasing irradiation dosage from $100 \mathrm{~Gy}$ to $140 \mathrm{~Gy}$ increased leaf chlorophyll concentration in $\mathrm{M}_{1}$ generation, but this effect was significantly reduced in $\mathrm{M}_{2}$ generation. The activities of superoxide dismutase (SOD), peroxidase (POD) and malondialdehyde (MDA) concentration all showed wider variation in $\mathrm{M}_{1}$ and $\mathrm{M}_{2}$ generation, the only exception being that the MDA concentration was similar to the control in the $\mathrm{M}_{2}$ generation. Overall, we suggest that treating soybean seeds with carbon ion beam irradiation at a dosage of $120 \mathrm{~Gy}(80 \mathrm{Mev} / \mathrm{u})$ could be effective in soybean mutation breeding.
\end{abstract}

Keywords: antioxidant enzymes; carbon ion beam; chlorophyll; mutant; phenotype; seeds composition; soybean

\section{Introduction}

Genetic mutation provides the possibility of creating new genotypes in which breeders can identify appropriate phenotypes with the desired genes [1]. In nature, the natural mutation rate is about $0.1 \%$, while the use of mutagenic agents such as radiation and chemicals can increase the mutation rate to up to 3\%, 100 or even 1000 times higher than natural mutations [2]. Thus, mutation breeding has been widely applied to create crop varieties and desired mutants [3]. So far, according to the database from the Joint Division of the Food and Agriculture Organization of United Nations and the International Atomic Energy Agency (FAO/IAEA, Viena, Austrial), 3299 mutants have been released (http://mvd.iaea.org/).

In general, there are two types of mutagens, chemical mutagens and physical mutagens. Ethyl methane sulfonate (EMS) is one of the most intensively used chemical mutagens because the required method is easy to implement, does not require complicated equipment and has high frequency point mutations [4]. Espina et al. [5]. and Li et al. [6] constructed an EMS mutant population in soybean and found diverse phenotypes, including seed shape and composition and plant morphology and maturity. Moreover, there was evidence that these traits can be stably inherited. However, chemical mutagens are generally carcinogenic since low-efficiency and low-toxicity chemicals are not available. Therefore, physical mutagenesis is more often used in plant breeding [7]. The earliest radiation-induced mutation 
breeding was implemented by American scientist L. J. Stadler, who first confirmed the induced effect of x-rays on barley in 1928 [8]. Gamma rays, x-rays, neutrons and lasers are the most commonly used physical mutagens. In soybean alone, many types of mutations have been created through these mutagens, including mutants with high oil and protein concentration of seeds [9], high yield and early maturity mutants, seed color mutants and lipoxygenase-lacking mutants [10].

Carbon ion beam radiation (CIBR) is a new physical mutagen with high linear energy transfer (LET) and relative biological effectiveness (RBE) in biological systems [11], which has been increasingly applied to mutagenesis breeding in various plants. Compared to other mutagenic resources, the most prominent characteristic of CIBR is that it can release a large amount of energy at the end of the target material by forming a sharp energy shape, which demonstrates a higher mutation frequency and broader spectrum [12,13].

Changes in germination rate, emergence rate, plant morphology, fertility, quality and other traits have been found by CIBR in arabidopsis, tobacco, rice and other crop plants $[14,15]$. Changes in DNA base and ribose, strand breaks, cross-linking with proteins and a higher mutation rate were also reported [16-18]. Furthermore, many novel mutants, which are barely identifiable by other mutagens have been obtained by CIBR, such as pink, red and yellow petals in carnations, the number of petals, flower size, shape and color mutants in roses, complex and striped color mutants in chrysanthemums [19] and multifarious compound leaves mutants and chlorophyll deficiency mutants in soybean [20]. Though phenotype variation is the most common method for screening mutants, many traits are not visually observed and thus cannot easily be screened out. Therefore, it is necessary to properly combine the detection of biochemical parameters [21].

Similar to other stress factors, radiation breaks the dynamic balance of free radical and reactive oxygen species (ROS) production and elimination in plants. In order to avoid or reduce the harmful effects of ROS, plants develop enzymatic antioxidants like superoxide dismutase (SOD) and peroxidase (POD) [22-24]. There is also evidence that proline (Pro) accumulation can reduce ROS levels [25]. In addition, the change of malondialdehyde (MDA) concentration, the most important product of membrane lipid peroxidation, is a good and commonly used response indicator under stress conditions [26]. In general, lower doses of ionizing radiations played a modulatory role for the growth and developmental processes of seedlings while higher doses of exposure induce growth inhibition [27,28]. With an increase of the radiation dose, the activity of antioxidant enzymes and the concentrations of MDA, proline and hydrogen peroxide were found to increase, but when the radiation dose increased to a certain extent, these related indicators decreased or changed slightly $[26,29,30]$.

In this study, the emergency and survival rates induced by CIBR for soybean variety Dongsheng 28 were investigated and the morphological and agronomic traits, seed morphology and seed composition in this mutant population were identified. In addition, biochemical parameters and their distribution in $\mathrm{M}_{1}$ and $\mathrm{M}_{2}$ plants in response to different irradiation doses were also examined. We anticipated that the determination of the optimal dose for mutagenesis and an understanding of early mutation effects could accelerate the application of CIBR in creating desired mutants and phenotypes in soybean breeding programs.

\section{Materials and Methods}

\subsection{Plant Materials and Irradiation Treatments}

The soybean variety Dongsheng 28 was used in this study. This variety has a high yield potential with wide adaptability and was released by the Northeast Institute of Geography and Agroecology of the Chinese Academy of Sciences. The irradiation treatments were conducted at the Institute of Modern Physics of the Chinese Academy of Sciences over two years (2017 and 2018). Dried soybean seeds of Dongsheng 28 with uniform size were chosen and divided into four groups of 100 seeds each to receive different doses of irradiation. The irradiation was set at 40 Gy per min with dosages of 0 (control), 70, 90 and 110 Gy in 2017 
and 0 (control), 100, 120 and $140 \mathrm{~Gy}$ in 2018. The irradiation was directly targeted at the hilum of each seed with an $80 \mathrm{Mev} / \mathrm{u}$ carbon ion beam.

The treated seeds were then planted in a field at the Agronomy Farm of the Northeast Institute of Geography and Agroecology of the Chinese Academy of Sciences $\left(45^{\circ} 73.2^{\prime} \mathrm{N}\right.$, $126^{\circ} 61.2^{\prime} \mathrm{E}$ ) in May. Each treatment of 100 seeds was sown in a single row $5 \mathrm{~m}$ long, with a row spacing of $45 \mathrm{~cm}$ and plant spacing of $5 \mathrm{~cm}$. The field was typical black soil with $29.3 \mathrm{~g} \mathrm{~kg}^{-1}$ organic matter content, $2.4 \mathrm{~g} \mathrm{~kg}^{-1}$ total $\mathrm{N}$ content, $1.5 \mathrm{~g} \mathrm{~kg}^{-1}$ total P content and $18.8 \mathrm{~g} \mathrm{~kg}^{-1}$ total $\mathrm{K}$ content. Before seeding, $70 \mathrm{~kg} \mathrm{ha}^{-1}$ diammonium phosphate, $98 \mathrm{~kg} \mathrm{ha}^{-1}$ urea and $120 \mathrm{~kg} \mathrm{ha}^{-1}$ potassium sulfate base fertilizers were applied. The experiment followed local recommended management methods for weed control and other agronomic practices. All survival plants were harvested separately in the $\mathrm{M}_{1}$ generation and every plant was sown in a single line in the $\mathrm{M}_{2}$ generation.

In the $\mathrm{M}_{1}$ generation, the number of seedlings was counted at 21 days after sowing and then the emergence rates were calculated. After emergence, all seedlings were observed every 2-3 days until the full maturity stage (R8); the survival rates were calculated by the number of surviving plants, including sterile plants, at different irradiation dosages. We measured plant height, branch number, node number, main stem diameter and bottom pod-setting height. The number of unproductive pods, number of productive pods per plant, number of seeds per plant, seed weight per plant, seed length and seed width per plant (the average of at least ten seeds randomly selected from each plant) were also measured. The seed protein and oil concentrations of all surviving plants that had at least $12 \mathrm{~g}$ of seeds were assayed by near infrared (NIR) spectroscopy (Perten IM9500, Sweden).

In the $\mathrm{M}_{2}$ generation, the emergence rates and survival rates of different single lines were calculated. For each single line, five seeds were harvested from every individual plant to form a block for the determination of seed protein and oil concentrations. Only mutants with changes in traits were harvested as individual plants and the same parameters were measured as in the $\mathrm{M}_{1}$ generation. These plants were continuously planted in the $\mathrm{M}_{3}$ generation.

\subsection{Measurement of Biochemical Parameters}

Sampling. At the R2 stage (one open flower at one of the two uppermost nodes on the main stem with a fully developed leaf), leaves on the same node (the third node counted from top to bottom) from all surviving plants were sampled from 9:00 am to 10:00 am local time in the $\mathrm{M}_{1}$ generation, while leaves of ten control plants were chosen randomly. Samples were put into a $10 \mathrm{~mL}$ centrifuge tube, frozen in liquid nitrogen and then stored in an ultra-low temperature freezer $\left(-80^{\circ} \mathrm{C}\right)$ for biochemical parameter determination. In the $\mathrm{M}_{2}$ generation, five plants were randomly selected from each plant line and then the leaves on the third node were sampled and wrapped together.

Extraction. The extraction of leaf samples for biochemical parameters was conducted following the methods of Asghar et al. [29] and Dhindsa et al. [31]. Briefly, about $0.5 \mathrm{~g}$ of leaf sample was homogenized in phosphate buffer $(\mathrm{pH}=7.8)$ and centrifuged at $10,000 \mathrm{rpm}$ for $20 \mathrm{~min}$ at $4{ }^{\circ} \mathrm{C}$. The supernatant was collected and used for the determination of SOD and POD activities and MDA concentration.

SOD Determination. Phosphate buffer ( $\mathrm{pH}=7.8$ ), $130 \mathrm{mM}$ methionine (Met), $750 \mu \mathrm{M}$ nitro blue tetrazolium chloride (NBT), $100 \mu \mathrm{M}$ EDTA- $\mathrm{Na}_{2}, 20 \mu \mathrm{M}$ riboflavin (FD) and $\mathrm{H}_{2} \mathrm{O}$ were mixed at a ratio of 15:3:3:3:3:2.5 for the extraction of SOD. Then, $20 \mu \mathrm{L}$ supernatant was added to $3 \mathrm{~mL}$ mixed liquid in a $10 \mathrm{~mL}$ centrifuge tube and placed under light at 4000 lux for $30 \mathrm{~min}$, before the reaction was terminated in the dark. The absorbance of the solution was read at $560 \mathrm{~nm}$ with a spectrophotometer (XinShiJi T6, Beijing, China). One unit of SOD was defined as the amount of enzyme required to cause $50 \%$ inhibition of nitro blue tetrazolium reduction.

POD Determination. A total of $28 \mu \mathrm{L}$ guaiacol was added to $50 \mathrm{~mL}$ phosphate buffer $(\mathrm{pH}=6.0)$, dissolved by magnetic stirring, cooled and uniformly mixed with $19 \mu \mathrm{L}$ of $30 \% \mathrm{H}_{2} \mathrm{O}_{2}$. Then, $20 \mu \mathrm{L}$ supernatant was added to $3 \mathrm{~mL}$ mixed liquid and changes in absorbance of the reaction solution at $470 \mathrm{~nm}$ were determined every $30 \mathrm{~s}$. 
MDA Concentration Determination. Homogenized $1 \mathrm{~mL}$ supernatant and $2 \mathrm{~mL} 5 \%$ TBA in a $10 \mathrm{~mL}$ centrifuge tube were placed in a boiling water bath for $15 \mathrm{~min}$, centrifuged at $4000 \mathrm{r} / \mathrm{min}$ for $10 \mathrm{~min}$ and then the supernatant was subjected to absorbance at $600 \mathrm{~nm}$, $532 \mathrm{~nm}$ and $450 \mathrm{~nm}$.

Chlorophyll Concentration Determination. Chlorophyll was determined using a method similar to that of Einhellig [32]. About $0.3 \mathrm{~g}$ of fresh-weight leaf sample was put into a $50 \mathrm{~mL}$ centrifuge tube and $15 \mathrm{~mL}$ of $95 \%$ ethyl alcohol added in sequence, which was then extracted over 24 to $36 \mathrm{~h}$ in the dark. The extract was then diluted ten times with $95 \%$ ethyl alcohol and the absorbance of the extracts was measured at $665 \mathrm{~nm}, 649 \mathrm{~nm}$ and $470 \mathrm{~nm}$ by spectrophotometer.

\subsection{Statistics Analysis}

One-way ANOVA $(p<0.05)$ was performed to analyze the differences in emergence rates and survival rates between irradiation doses. A Box plot was created to compare the differences among other physiological indicators. The box plot plots the median, 10th, 25th, 75th and 90th percentiles as vertical boxes with error bars. Each box contains the data of a survival plant at every irradiation dose. The figures were all created with Graphpad Prism8.

\section{Results}

\subsection{Effects of CIBR on Emergence Rate and Survival Rate in the $M_{1}$ and $M_{2}$ Generations}

Our previous report suggested that $100 \mathrm{~Gy}$ of carbon ion beam irradiation could be applied in soybean mutation breeding through the screening of 100, 150, 200, 300 and 400 Gy dosages [33]. In 2017, we further refined the experiment with irradiation doses of 70, 90 and 110 Gy. Though there was no significant difference between the control (78\%) and $110 \mathrm{~Gy}$ treatment $(71 \%)$ for the emergency rate $(p<0.05)$, the values of the emergence counts minus the final plant counts for the irradiance treatments of 70,90, and $110 \mathrm{~Gy}$ were $49 \%, 44 \%$ and $62 \%$, respectively; higher than that of the control (5\%). Compared to 2017 , the emergence rate in 2018 decreased obviously. Significant differences were found between the control and $100 \mathrm{~Gy}$ treatments for both emergence rate and survival rate, while the decreases in the $120 \mathrm{~Gy}$ and $140 \mathrm{~Gy}$ treatments were not significant. Although no significant difference was found between $120 \mathrm{~Gy} \mathrm{(33 \% )} \mathrm{and} 140 \mathrm{~Gy}$ (31\%) for the emergence rate, the survival rate of $140 \mathrm{~Gy}$, at 18\%, was obviously lower than that of $120 \mathrm{~Gy}$, at 27\% (Figure 1).
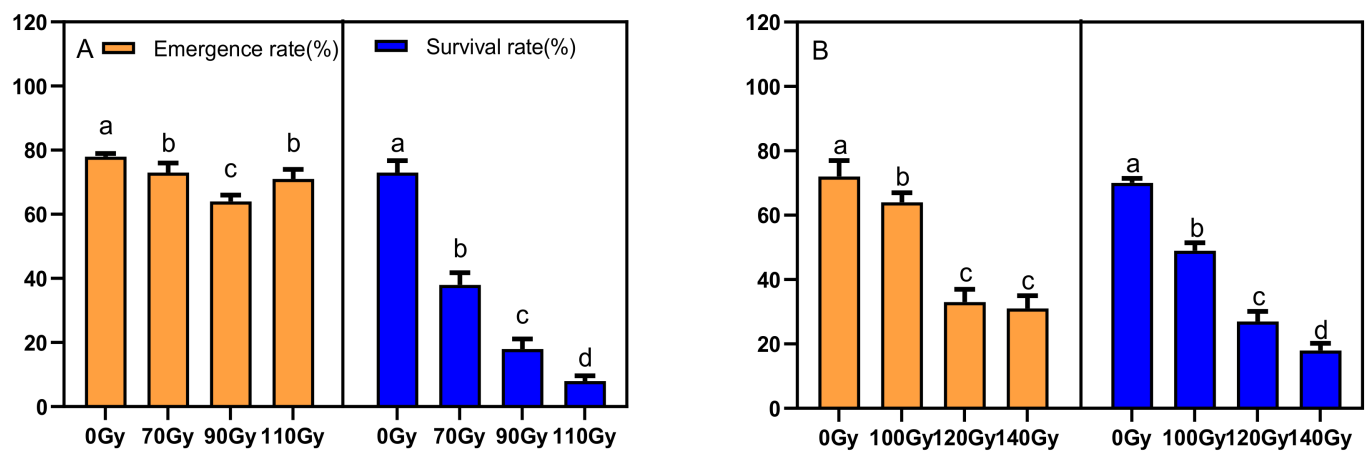

Figure 1. Effects of ${ }^{12} \mathrm{C}^{6+}$ carbon ion beam irradiation on emergence rate and survival rate in the $\mathrm{M}_{1}$ generation. Means with different letters are significantly different at $p \leq 0.05$. (A) The emergence rate and survival rate of different irradiation doses in 2017. (B) The emergence rate and survival rate of different irradiation doses in 2018.

Irradiation-induced mutation also affected the emergence rate and survival rate in the $\mathrm{M}_{2}$ generation. In order to better compare the effects of different radiation doses on the emergence rates from different family lines, we divided the emergence rate into five levels, as shown in Figure 2. In 2017, only 50\% of the lines showed higher emergence rates of $80 \%$ to $100 \%$, and in 2018 , with the increase in irradiation dose, the percentage of the lines with an emergence rate over $80 \%$ decreased to $20 \%$. 

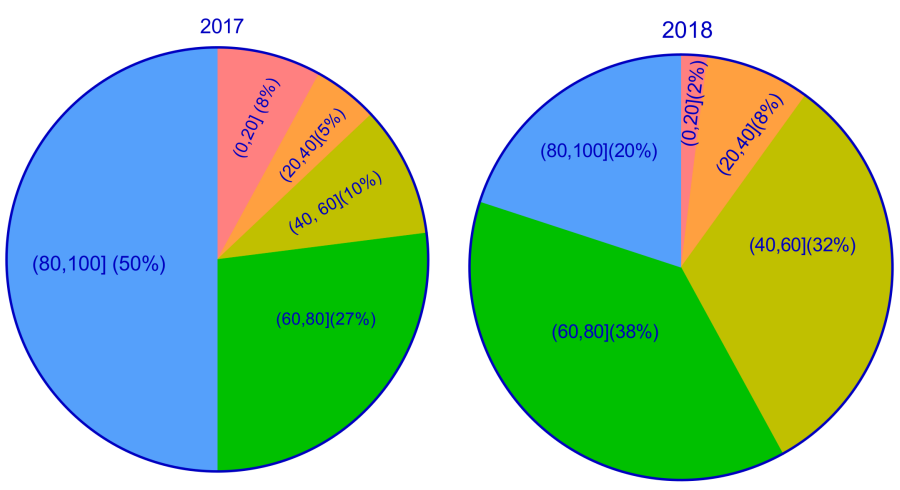

Figure 2. Emergence rate percentages in $\mathrm{M}_{2}$ families.

\subsection{Screening for Visual Morphological Traits Mutants}

In the $\mathrm{M}_{1}$ generation, compared to the control plants, the emergence of radiationtreated seeds was delayed by $3-5$ days and the plants grew more slowly during the seedling stage. However, this phenomenon disappeared in the $\mathrm{M}_{2}$ generation and many mutants with visible phenotype changes were identified. The most striking phenotypic variations observed during the growing period were altered leaves and stems, including pentafoliate leaves (Figure 3C,D), tetrafoliate leaves (Figure 3E), deformed leaves mutant (Figure 3F), the mutant with bent downward leaves (Figure 3G) and the mutant with double main stem (Figure 3I). With regard to mutants with multicompound leaves, the leaves over the whole plants were all pentafoliate leaves or tetrafoliate leaves. Unfortunately, these mutants were all dead before the pod-setting stage. Many plants showed the traits of double main stems (Figure $3 \mathrm{I}$ ) in the $\mathrm{M}_{1}$ generation, but these traits disappeared in the next generation. In the $\mathrm{M}_{2}$ generation, at the seedling stage, we found many seedlings with two pairs of unifoliolate leaves (Figure 3A) and yellowing of unifoliolate leaves (Figure 3B). Thickening and shrinkage of cotyledons were also observed but they could have been useless variations and we did not propagate them in the next generation.

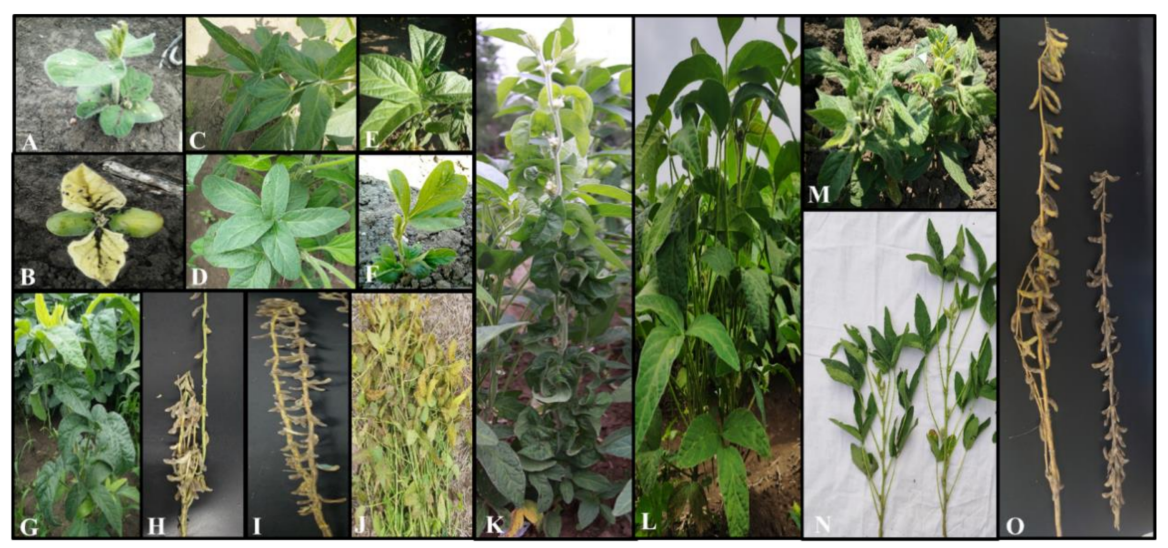

Figure 3. Examples of phenotypes observed in ${ }^{12} \mathrm{C}^{6+}$ carbon ion beam-induced soybean population. (A) Yellowing unifoliolate leaves mutant. (B) Two pairs of unifoliolate leaves mutant. (C,D) Pentafoliate leaves mutant. (E) Terafoliate leaves mutant. (F) Deformed leaves mutant. (G) Leaves bent downward mutant. (H) Multibranches mutant. (I) Double main stem mutant. (J) Sterile plants mutant. (K) Rolled leaves and short petioles mutant. (L) Control plants. (M) Multileaves mutant. (N) Short height mutant (on the right is the control). (O) Short growth period mutant (on the left is the control).

We also observed many variations that had genetic predispositions. As shown in Figure $3 K$, we found a mutant with the leaf curled downwards at $90 \mathrm{~Gy}$ in the $\mathrm{M}_{1}$ generation. This mutant had a very short petiole, erected at the lower part and crept at the upper part of the plant, which still showed character separation until the fourth generation. Furthermore, in one line we found mutants with narrow and slender leaves but plant heights less than 
$20 \mathrm{~cm}$ (Figure 3M). On the same plants, trifoliate, pentafoliate and hexafoliate existed simultaneously and the plants could flower normally but could not bear seeds. We also found sterile plants in two lines (Figure 3J) and a large number of sterile plants were still found in the third generation. Surprisingly, we found a special mutant population in which there was significant separation in growth period traits and plant height traits in the $\mathrm{M}_{3}$ generation: the plant height was reduced by about $50 \%$ and the growth period was either 15 days longer or 15 days shorter than normal (Figure $3 \mathrm{~N}, \mathrm{O}$ ). We also screened out eight yield-related and 15 lodging-resistant candidate mutant lines, since environmental factors have a greater impact on these traits and genetic stability would need to be verified.

\subsection{Effects of Carbon Ion Beam Radiation on Seeds Size and Seed Composition}

In order to better quantify the changes in seed morphology and composition of the mutagenized progeny, we measured the seed length, seed width and the concentrations of seed protein and oil for the individual plants in 2018. The $\mathrm{M}_{1}$ population generally showed significant variations in seed traits (Figure 4). Generally, the irradiation treatments produced larger seeds, with seed lengths ranging from $7.5 \mathrm{~mm}$ to $8.0 \mathrm{~mm}$, and seed width from $6.0 \mathrm{~mm}$ to $7.5 \mathrm{~mm}$, compared to the seeds of the control plants $(7.20 \mathrm{~mm}$ to $7.52 \mathrm{~mm}$ seed lengths and $6.19 \mathrm{~mm}$ to $6.58 \mathrm{~mm}$ seed widths). The $120 \mathrm{~Gy}$ treatment resulted in the most extensive variation (Figure $4 \mathrm{~A}, \mathrm{~B}$ ). The radiation treatments increased the number of unproductive pods, one-seed pods and two-seed pods, but decreased the number of three-seed pods and four-seed pods, compared to the control. As shown in Figure $4 C$, the ratio of seed to pod was greater (2.5 to 3.5) for the control than for the irradiation treatments (1.0 to 2.5). Surprisingly, the increase in the number of one- pod and two-seed pods did not lead to a decline in yield due to higher number of pods with heavier seeds in the mutants. For example, one mutant produced 94 one-seed pods and 42 two-seed pods and its single plant seed weight was $52.79 \mathrm{~g}$, which was $109 \%$ higher than the control plants. Another mutant resulting from the 140 Gy treatment had 61 one- and two-seed pods and 87 threeand four-seed pods, with the single plant seed weight reaching $77.53 \mathrm{~g}$, which was about four times greater than the control. Many mutants with significantly altered seed sizes were also identified in the $\mathrm{M}_{2}$ generation, including some of the mutants mentioned above. These mutants continued to show a tendency of stable inheritance in the $\mathrm{M}_{3}$ generation. Thus, when the traits were heritable and stable in the later generation, they produced extraordinarily high yields and had larger seed germplasms.

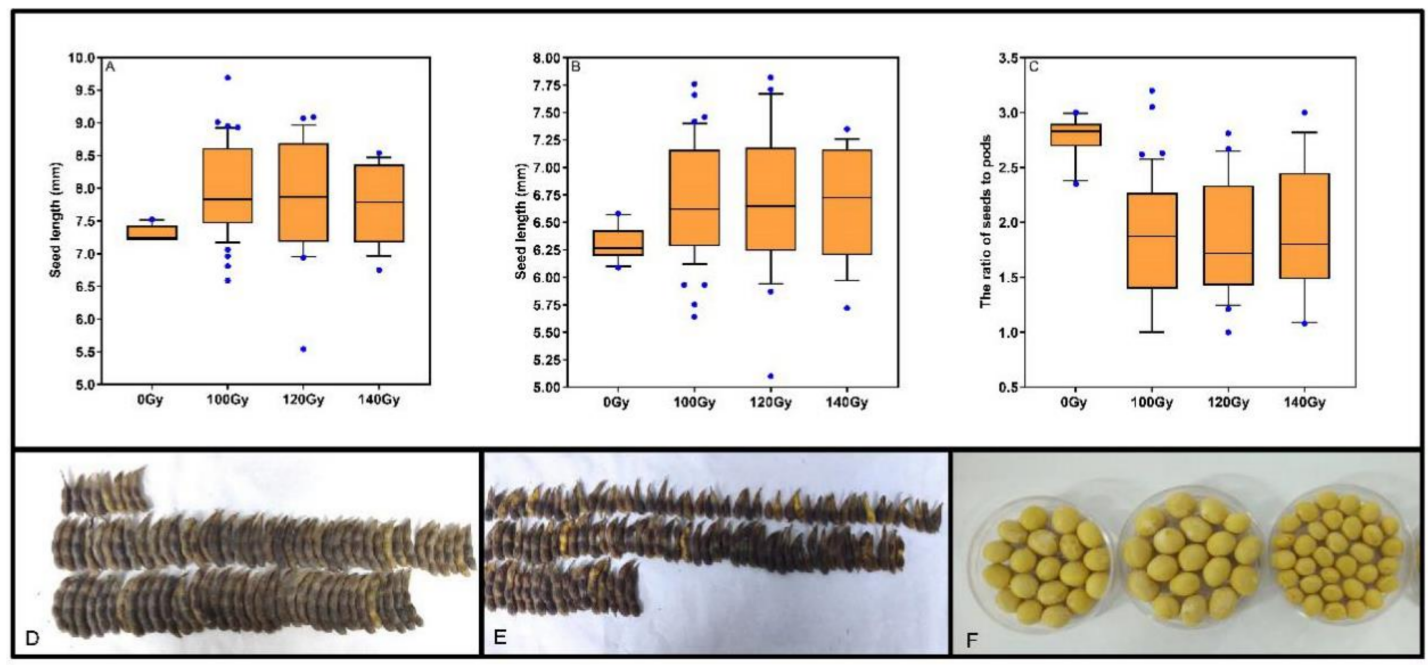

Figure 4. Distributions of seed length, seed width and ratio of seeds to pods in the M1 population. (A) Seed width; (B) seed length; (C) ratio of seeds to pods; (D) pods of WT; (E) pods of mutants with more one- and two-seed pods; (F) mutants with altered seed sizes (from left to right: WT, lager seeds mutant, smaller seeds). 
For mutants that produced at least $12 \mathrm{~g}$ of seeds, we performed a, NIR analysis (Figure 5) to determine seed quality traits in the $M_{1}$ and $M_{2}$ generations. In the $M_{1}$ generation, the range of protein concentration was $35.1-46.5 \%$ and most of the plants had higher seed protein concentrations, especially for the higher irradiation dose of $140 \mathrm{~Gy}$. In the $\mathrm{M}_{2}$ generation, the range of protein concentration was $38.5-42.9 \%$ and the median values of the three irradiation doses were similar. In the $\mathrm{M}_{1}$ generation, the oil concentration for the irradiation treatments also showed significant variation, ranging from $16.2-20.8 \%$, but was lower in most of the plants. In the $\mathrm{M}_{2}$ generation, lower oil concentrations at $100 \mathrm{~Gy}$ but concentrations at $120 \mathrm{~Gy}$ and $140 \mathrm{~Gy}$, with a range of $18.8-23.8 \%$, were found in most of the plants. The change of total protein and oil concentration in the $\mathrm{M}_{1}$ generation was not obvious but in the $\mathrm{M}_{2}$ generation higher total protein and oil concentration was found for higher irradiation doses (120 Gy and $140 \mathrm{~Gy}$ ).
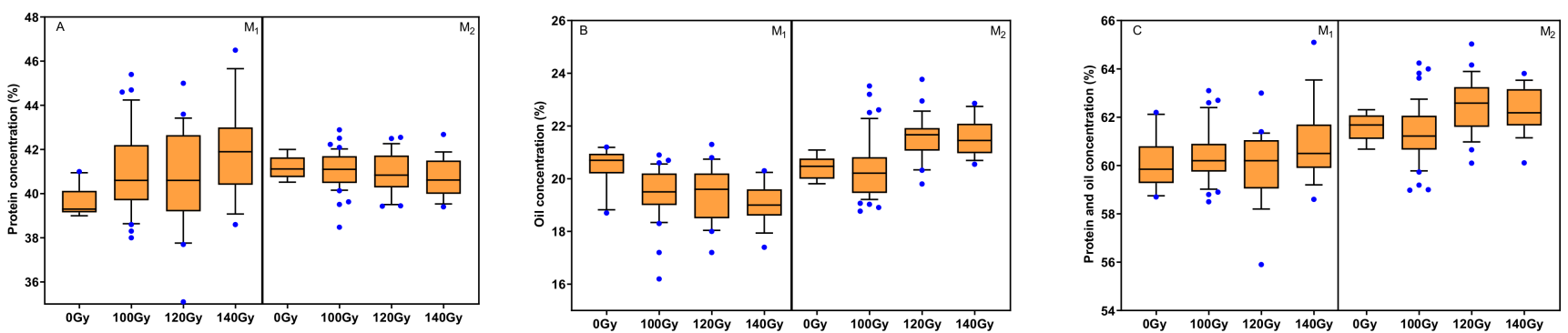

Figure 5. The distribution of seed protein concentration and oil concentration in the $\mathrm{M}_{1}$ and $\mathrm{M}_{2}$ populations. (A) Protein concentration; (B) oil concentration; (C) protein and oil concentration.

\subsection{Effects of Carbon Ion Beam Radiation on Chlorophyll Concentration}

The concentrations of chlorophyll-a, chlorophyll-b and carotenoid and the total chlorophyll in the $M_{1}$ and $M_{2}$ generations according to different dosages at the $R 2$ stage are shown in Figure 6. In the $\mathrm{M}_{1}$ generation, with the increase in irradiation dose, the chlorophyll-a concentration showed a decreasing tendency and all irradiation doses obviously increased the chlorophyll-b concentration and carotenoid concentration. For the total chlorophyll concentration, the median values were all higher for the irradiation treatments than for the control, though those of the 140 Gy treatment was lower than that of the 100 and 120 Gy treatments. In the $\mathrm{M}_{2}$ generation, the ranges of chlorophyll-a, chlorophyll-b, carotenoid and total chlorophyll concentrations were not wide compared to the $\mathrm{M}_{1}$ generation and the median values of chlorophyll-a and chlorophyll-b concentrations of the irradiation treatments were similar to the control. The median values of carotenoid concentration in the irradiation treatments were higher than that of the control, especially at 120 Gy. However, the concentrations of total chlorophyll in all irradiation treatments were lower than in the control, especially at $140 \mathrm{~Gy}$.

\subsection{Effects of Carbon Ion Beam Radiation on Antioxidant Enzyme Activities and MDA Concentration}

In the $\mathrm{M}_{1}$ generation, it was observed that 120 and $140 \mathrm{~Gy}$ irradiation treatments enhanced the activity of SOD, with 120 Gy showing a greater variability. In the $\mathrm{M}_{2}$ generation, a wider range of SOD activities relative to the $\mathrm{M}_{1}$ generation was found but the median values were all below the control (Figure 7A). Greater variability for POD activities in the $\mathrm{M}_{1}$ generation was also found for the $120 \mathrm{~Gy}$ treatment and a larger proportion of POD activities were greater than the median for the 120 and 140 Gy groups. In the $\mathrm{M}_{2}$ generation, the POD activities of irradiation treatment were generally higher than in the control (Figure 7B). The 120 Gy treatment in the $\mathrm{M}_{1}$ generation induced greater variability for MDA concentrations and those over the median accounted for a larger proportion, but no similar variations were found at 100 and $140 \mathrm{~Gy}$. In the $\mathrm{M}_{2}$ generation, the variation of MDA concentrations in irradiation treatments was not wider than that in the $\mathrm{M}_{1}$ generation (Figure $7 \mathrm{C}$ ). 

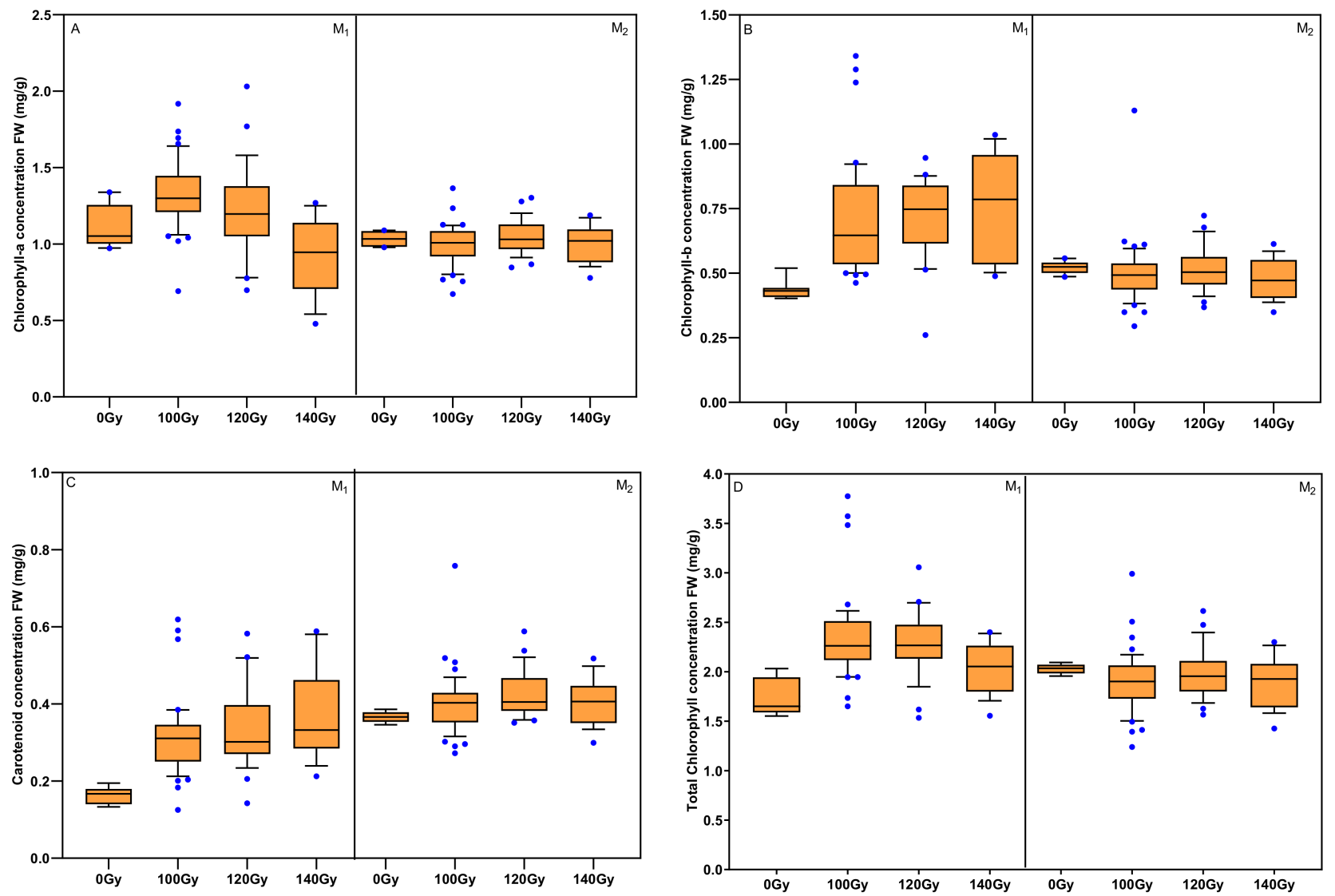

Figure 6. Chlorophyll-a, chlorophyll-b, carotenoid and total chlorophyll concentrations in the $\mathrm{M}_{1}$ and $\mathrm{M}_{2}$ generations at different irradiation dosages. (A) Chlorophyll-a. (B) Chlorophyll-b. (C) carotenoid. (D) Total chlorophyll
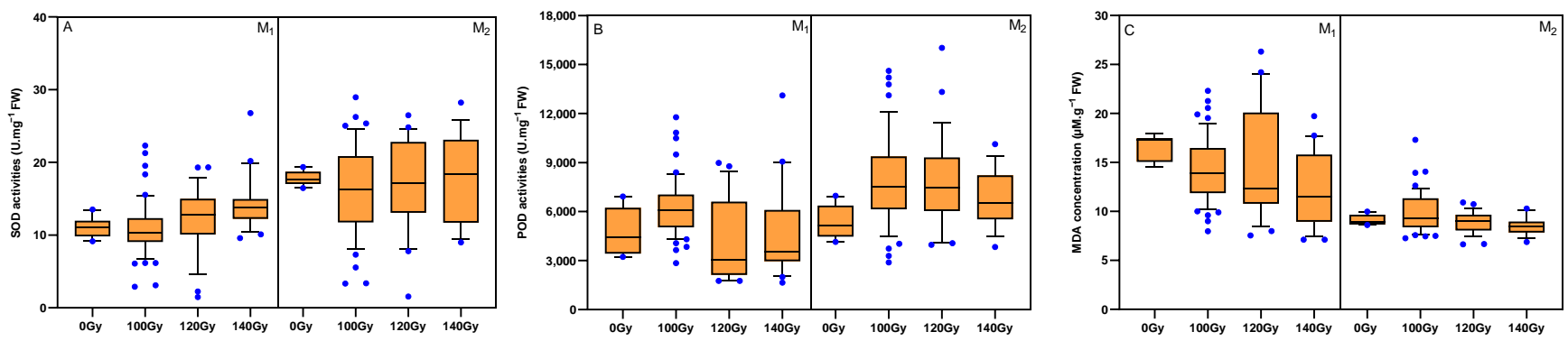

Figure 7. Effects of different radiation doses on antioxidant enzyme activities and MDA concentrations in the $\mathrm{M}_{1}$ and $\mathrm{M}_{2}$ generations. (A) SOD activities; (B) POD activities; (C) MDA concentration.

\section{Discussion}

The optimal radiation dose determines the success of mutation breeding [34]. In order to ensure high mutation frequency with more beneficial mutants and obtain sufficient viable seeds at the same time, a dose causing $50 \%$ lethality is often chosen as the optimal radiation dose [1]. Emergence and survival rates decreasing with an increase of the irradiation dose has been reported [35,36] but, in the present study, we found that the 70, 90 and 110 Gy treatments generally showed lower survival but higher emergence rates. We demonstrated that the range of 70 to $90 \mathrm{~Gy}$ might not be enough for getting sufficient mutants and that the lower survival rate is probably due to the weaker resistance of the seedlings after radiation and the combined influence of environmental factors. This was also supported by the significant decline of the emergence rate in the $M_{1}$ and $M_{2}$ generations from 120 to $140 \mathrm{~Gy}$. We found that the $120 \mathrm{~Gy}$ treatment had a similar emergence rate to the $140 \mathrm{~Gy}$ treatment but a higher survival rate, which is more suitable for mutation breeding of 
soybean. Therefore, to obtain more mutants, higher doses might be a good choice for carbon ion beam irradiation.

The present study identified many novel phenotype mutants with heritable tendencies, including plant height mutants, sterile mutants, early mature mutants, rolled leaves and short petioles mutants, seed size alteration mutants, yield-related mutants and lodgingresistant mutants. Similar phenotype changes have also been also found with the EMS mutagen $[5,6]$. However, the mutant we found with rolled leaves and short petioles has never been reported. The mutants obtained in this study, not only provide germplasms resource for breeding, but also could be good materials for studying hormone metabolism, photosynthesis and growth habits, while the early maturity and lodging resistance candidate mutants are of great significance for the improvement of the original varieties.

Significant increases or decreases in seed protein and oil concentrations in mutants across multiple generations and environments as a result of radiation have been reported [9]. Higher concentrations of EMS were effective in increasing the variability for fatty acid content in soybean oil [37]. We also found that higher irradiation doses were more effective in increasing the oil concentration, as well as the total protein and oil concentration. The wider range of protein and oil concentrations in the $\mathrm{M}_{1}$ generation was probably not inheritable; therefore, in soybean breeding, the selection of high-oil and high-protein mutants should start in the $\mathrm{M}_{2}$ generation and CIBR could be a good approach to screening for germplasm resources with large seed sizes and high protein and oil concentrations.

Chlorophyll-a, chlorophyll-b and carotenoids are important pigments in photosynthesis [38] and they are also important biochemical indicators for measuring the degree of radiation damage in mutation breeding. Many investigations have indicated that radiation mutagenesis has a higher probability of screening for chlorophyll-related mutants [39,40]. In contrast to the results of Alilamamogul et al. [22], who found that chlorophyll-a, chlorophyll-b and total chlorophyll were negatively affected by radiation, our results showed that, except for a decreased concentration of chlorophyll-a in the 140 Gy treatment in the $\mathrm{M}_{1}$ generation, the irradiation treatments consistently increased chlorophyll-a, chlorophyll-b, carotenoid and total chlorophyll concentrations. However, this effect was significantly decreased in the $\mathrm{M}_{2}$ generation, which implies that the positive effect of irradiation on chlorophyll concentration in the $\mathrm{M}_{1}$ generation may not be inherited in the next generation.

Physiological level variations caused by radiation reported by previous researchers were mostly concentrated in seeds or seedlings and demonstrated that ionizing radiation increased the activities of catalase (CAT), SOD and POD, which are well correlated with the enhancement of growth $[29,41,42]$. In our study, SOD and POD activities in the $\mathrm{M}_{1}$ and $\mathrm{M}_{2}$ generations both showed wider variation, especially at $120 \mathrm{~Gy}$, which indicates that CIBR can, to a certain extent, improve the ability of some plants to protect against free radical damage. As a good and commonly used response indicator under stress conditions, MDA concentration is the most important product of membrane lipid peroxidation [26]. The MDA concentrations for irradiation treatments in our study showed diverse variability in the $\mathrm{M}_{1}$ generation, but not in the $\mathrm{M}_{2}$ generation, which indicated that the physiological damage caused by CIBR was significantly restored in the $\mathrm{M}_{2}$ generation. In summary, we propose that the emergence rate, the survival rate, the beneficial mutation rate, environment conditions and some biochemical parameters should be all considered in order to determine the optimal dose of CIBR accurately. We will continue to observe the physiological changes in later generations to judge whether the determination of the biochemical indicator of the mutant population could be used as one of the criteria for screening the optimal radiation dose and the specific mutant.

Author Contributions: Methodology, X.W. and C.-K.L.; formal analysis, X.W. and B.-J.T.; investigation, X.W., C.-K.L., B.-J.T. and Y.-S.L.; resources, Y.-S.L. and Q.-Y.Z.; writing-original draft preparation, X.W.; writing-review and editing, Q.-Y.Z. and X.-B.L.; supervision, Q.-Y.Z. and X.-B.L.; project administration, Q.-Y.Z. and X.-B.L.; funding acquisition, Q.-Y.Z. All authors have read and agreed to the published version of the manuscript. 
Funding: This work was partially funded by the Major Program of National Science and Technology of China, grant number 2016YFD0102105 and the Strategic Priority Research Program of the Chinese Academy of Sciences, grant number XDA24030403-3.

Institutional Review Board Statement: Not applicable.

Informed Consent Statement: Not applicable.

Data Availability Statement: The data presented in this study are available on request from the corresponding author.

Acknowledgments: The authors are grateful to Baoluo Ma for guidance on biochemical experiment and editing the manuscript.

Conflicts of Interest: The authors declare no conflict of interest.

\section{References}

1. Oladosu, Y.; Rafii, M.Y.; Abdullah, N.; Hussin, G.; Ramli, A.; Rahim, H.A.; Miah, G.; Usman, M. Principle and application of plant mutagenesis in crop improvement: A review. Biotechnol. Biotechnol. Equip. 2016, 30, 1-16. [CrossRef]

2. Singh, M.P.; Kumar, S. Genetics and Plant Breeding; APH Publishing Corporation: New Delhi, India, 2009.

3. Novak, F.J.; Brunner, H. Plant breeding: Induced mutation technology for crop improvement. IAEA Bull. 1992, 4, 25-33.

4. Lee, D.K.; Kim, Y.S.; Kim, J.K. Determination of the optimal condition for Ethyl methane sulfonate-mediated mutagenesis in a Korean commercial rice, Japonica cv. Dongjin. Appl. Biol. Chem. 2017, 60, 241-247. [CrossRef]

5. Espina, M.J.; Sabbir Ahmed, C.M.; Angelina, B.; Ekundayo, A.; Zeinab, Y.; Prakash, A.; Vince, P.; Ali, T. Development and phenotypic screening of an ethyl methane sulfonate mutant population in soybean. Front. Plant. Sci. 2018, 9, 394. [CrossRef]

6. Li, Z.; Jiang, L.; Ma, Y.; Wei, Z.; Hong, H.; Liu, Z.; Lei, J.; Liu, Y.; Guan, R.; Guo, Y.; et al. Development and utilization of a new chemically-induced soybean library with a high mutation density. J. Integr. Plant Biol. 2017, 59, 60-74. [CrossRef] [PubMed]

7. Mba, C.; Afza, R.; Bado, S.; Jain, S.M. Induced Mutagenesis in Plants Using Physical and Chemical Agents. In Plant Cell Culture; Wiley \& Sons: Hoboken, NJ, USA, 2010; pp. 111-130.

8. Stadler, L.J. Mutations in Barley Induced by X-Rays and Radium. Science 1928, 68, 186-187. [CrossRef]

9. Bolon, Y.-T.; Haun, W.J.; Xu, W.W.; Grant, D.; Stacey, M.G.; Nelson, R.T.; Gerhardt, D.J.; Jeddeloh, J.A.; Stacey, G.; Muehlbauer, G.J.; et al. Phenotypic and Genomic Analyses of a Fast Neutron Mutant Population Resource in Soybean. Plant Physiol. 2011, 156, 240-253. [CrossRef]

10. Ha, B.-K.; Lee, K.J.; Velusamy, V.; Kim, J.-B.; Kim, S.H.; Ahn, J.-W.; Kang, S.-Y.; Kim, D.S. Improvement of soybean through radiation-induced mutation breeding techniques in Korea. Plant Genet. Res. 2014, 12, S54-S57. [CrossRef]

11. Kraft, G. Tumor therapy with heavy charged particles. Prog. Part. Nucl. Phys. 2000, 45, S473-S544. [CrossRef]

12. Zhao, S.G.; Tang, M.L.; Wang, J.; Wang, T.; Wang, S.C.; Wu, Y.J.; Yu, Z.L. Mutagenic effects of BM302:Go112 induced by low-energy ion beam implantation. Plasma. Sci. Technol. 2007, 9, 508-512.

13. Becker, D.; Razskazovskii, Y.; Callaghan, M.U.; Sevilla, M.D. Electron Spin Resonance of DNA Irradiated with a Heavy-Ion Beam $\left({ }^{16} \mathrm{O}^{8+}\right)$ : Evidence for Damage to the Deoxyribose Phosphate Backbone. Radiat. Res. 1996, 146, 361. [CrossRef]

14. Hase, Y.; Nozawa, S.; Narumi, I.; Oono, Y. Effects of ion beam irradiation on size of mutant sector and genetic damage in Arabidopsis. Nucl. Instrum. Methods Phys. Res. Sect. B Beam Interact. Mater. Atoms 2017, 391, 14-19. [CrossRef]

15. Tanaka, A.; Shikazono, N.; Hase, Y. Studies on Biological Effects of Ion Beams on Lethality, Molecular Nature of Mutation, Mutation Rate, and Spectrum of Mutation Phenotype for Mutation Breeding in Higher Plants. J. Radiat. Res. 2010, 51, 223-233. [CrossRef] [PubMed]

16. Luo, S.; Zhou, L.; Li, W.; Du, Y.; Yu, L.; Feng, H.; Mu, J.; Chen, Y. Mutagenic effects of carbon ion beam irradiations on dry Lotus japonicus seeds. Nucl. Instrum. Methods Phys. Res. Sect. B Beam Interact. Mater. Atoms 2016, 383, 123-128. [CrossRef]

17. Shikazono, N.; Tanaka, A.; Watanabe, H.; Tano, S. Rearrangements of the DNA in carbon ion-induced mutants of Arabidopsis thaliana. Genet. 2001, 157, 379-387.

18. Shikazono, N.; Yokota, Y.; Tanaka, A.; Watanabe, H.; Tano, S. Molecular analysis of carbon ion-induced mutations in Arabidopsis thaliana. Genes Genet. Syst. 1998, 73, 173-179. [CrossRef] [PubMed]

19. Yamaguchi, H.; Hase, Y.; Tanaka, A.; Shikazono, N.; Degi, K.; Shimizu, A.; Morishita, T. Mutagenic effects of ion beam irradiation on rice. Breed. Sci. 2009, 59, 169-177. [CrossRef]

20. Mikuriya, S.; Kasai, M.; Nakashima, K.; Natasia; Hase, Y.; Yamada, T.; Abe, J.; Kanazawa, A. Frequent generation of mutants with coincidental changes in multiple traits via ion-beam irradiation in soybean. Genes Genet. Syst. 2017, 92, 153-161. [CrossRef]

21. Roychowdhury, R.; Datta, S.; Gupta, P.; Tah, J. Analysis of Genetic Parameters on Mutant Populations of Mungbean (Vigna radiata L.) after Ethyl Methane Sulphonate Treatment. Not. Sci. Biol. 2012, 4, 137-143. [CrossRef]

22. Alikamanoglu, S.; Yaycili, O.; Sen, A. Effect of gamma radiation on growth factors, biochemical parameters, and accumulation of trace elements in soybean plants (Glycine maxl. Merrill). Biol. Trace. Elem. Res. 2011, 141, 283-293. [CrossRef]

23. Rahman, M.M.; Rahman, M.M.; Chongling, Y.; Islam, K.S. Changes in growth and antioxidant enzymes activities during cadmium stress in the mangrove plant Kandelia candel (L.) Druce. Aes. Bioflux. 2010, 2, 15-24. 
24. Apel, K.; Hirt, H. Reactive oxygen species: Metabolism, oxidative stress, and signal transduction. Annu. Rev. Plant Biol. 2004, 55, 373-399. [CrossRef]

25. Kocsy, G.; Laurie, R.; Szalai, G.; Szilágyi, V.; Galiba, G.; De Ronde, J.A.; Simon-Sarkadi, L. Genetic manipulation of proline levels affects antioxidants in soybean subjected to simultaneous drought and heat stresses. Physiol. Plant. 2005, 124, 227-235. [CrossRef]

26. Moussa, H. Low dose of gamma irradiation enhanced drought tolerance in soybean. Bulg. J. Agric. Sci. 2011, 17, 63-72. [CrossRef]

27. Jan, S.; Parween, T.; Siddiqi, T.O.; Mahmooduzzafar. Gamma radiation effects on growth and yield attributes of Psoralea corylifolia L. with reference to enhanced production of psoralen. Plant Growth Regul. 2010, 64, 163-171.

28. Maity, J.; Mishra, D.; Chakraborty, A.; Saha, A.; Santra, S.; Chanda, S. Modulation of some quantitative and qualitative characteristics in rice (Oryza sativa L.) and mung (Phaseolus mungo L.) by ionizing radiation. . Radiat. Phys. Chem. 2005, 74, 391-394.

29. Asghar, T.; Jamil, Y.; Iqbal, M.; Haq, Z.-U.; Abbas, M. Laser light and magnetic field stimulation effect on biochemical, enzymes activities and chlorophyll contents in soybean seeds and seedlings during early growth stages. J. Photochem. Photobiol. B Biol. 2016, 165, 283-290. [CrossRef] [PubMed]

30. Jan, S.; Parween, T.; Siddiqi, T.; Mahmooduzzafar. Effect of gamma radiation on morphological, biochemical, and physiological aspects of plants and plant products. Environ. Rev. 2012, 20, 17-39. [CrossRef]

31. Dhindsa, R.S.; Plumb-Dhindsa, P.; Thorpe, T.A. Leaf Senescence: Correlated with Increased Levels of Membrane Permeability and Lipid Peroxidation, and Decreased Levels of Superoxide Dismutase and Catalase. J. Exp. Bot. 1981, 32, 93-101. [CrossRef]

32. Einhellig, F.A.; Rasmussen, J.A. Effects of three phenolic acids on chlorophyll content and growth of soybean and grain sorghum seedlings. J. Chem. Ecol. 1979, 5, 815-824. [CrossRef]

33. Zhang, Q.Y.; Yu, L.X.; Li, Y.S.; Du, Y.; Li, W.J.; Liu, X.B. Preliminary investigation of acceptable heavy ion beam irradiation dosage treated to soybean seed. Soyb. Sci. 2013, 32, 587-590. (Chinese with English Summary)

34. Kaul, M.L.H.; Bhan, A.K. Mutagenic effectiveness and efficiency of EMS, DES and gamma-rays in rice. Theor. Appl. Genet. 1977, 50, 241-246. [CrossRef] [PubMed]

35. Omar, S.R.; Ahmed, O.H.; Saamin, S.; Majid, N.M.A. Gamma radio sensitivity study on chili (Capsicum annuum); Technical report. Am. J. Appl. Sci. 2008, 5, 67-70.

36. Chaudhuri, S.K. A simple and reliable method to detect gamma irradiated lentil (Lens culinaris Medik.) seeds by germination efficiency and seedling growth test. Radiat. Phys. Chem. 2002, 64, 131-136. [CrossRef]

37. Patil, A.; Tawaresp, S.P.; Oak, M.D.; Tamhankar, S.A.; Rao, V.S. Improvement of oil quality in soybean [Glycine max (L.) Merrill] by mutation breeding. J. Am. Oil. Chem. Soc. 2007, 84, 1117-1124. [CrossRef]

38. Adams, W.W.; Winter, K.; Schreiber, U.; Schramel, P. Photosynthesis and Chlorophyll Fluorescence Characteristics in Relationship to Changes in Pigment and Element Composition of Leaves of Platanus occidentalis L. during Autumnal Leaf Senescence. Plant Physiol. 1990, 92, 1184-1190. [CrossRef]

39. Sakowska, K.; Alberti, G.; Genesio, L.; Peressotti, A.; Vedove, G.D.; Gianelle, D.; Colombo, R.; Rodeghiero, M.; Panigada, C.; Juszczak, R.; et al. Leaf and canopy photosynthesis of a chlorophyll deficient soybean mutant. Plant Cell Environ. 2018, 41, 1427-1437. [CrossRef]

40. Arase, S.; Hase, Y.; Abe, J.; Kasai, M.; Yamada, T.; Kitamura, K.; Narumi, I.; Tanaka, A.; Kanazawa, A. Optimization of ion-beam irradiation for mutagenesis in soybean: Effects on plant growth and production of visibly altered mutants. Plant Biotechnol. 2011, 28, 323-329. [CrossRef]

41. Jamil, Y.; Perveen, R.; Ashraf, M.; Ali, Q.; Iqbal, M.; Ahmad, M.R. He-Ne laser-induced changes in germination, thermodynamic parameters, internal energy, enzyme activities and physiological attributes of wheat during germination and early growth. Laser Phys. Lett. 2013, 10, 45606. [CrossRef]

42. Aly, A.; El-Beltagi, H. Influence of ionizing irradiation on the antioxidant enzymes of Viciafaba L. Grasas Aceites 2010, 61, 288-294. [CrossRef] 